\title{
Bruno Blanckeman, Sylvie Germain : le livre des livres
}

\section{Elisa Bricco}

\section{(2) OpenEdition}

\section{Journals}

\section{Edizione digitale}

URL: https://journals.openedition.org/studifrancesi/41307

DOI: 10.4000/studifrancesi.41307

ISSN: 2421-5856

\section{Editore}

Rosenberg \& Sellier

\section{Edizione cartacea}

Data di pubblicazione: 1 juillet 2004

Paginazione: 225

ISSN: 0039-2944

\section{Notizia bibliografica digitale}

Elisa Bricco, «Bruno Blanckeman, Sylvie Germain : le livre des livres», Studi Francesi [Online], 142 (XLVIII I I) | 2004, online dal 30 novembre 2015, consultato il 09 septembre 2021. URL: http://

journals.openedition.org/studifrancesi/41307; DOI: https://doi.org/10.4000/studifrancesi.41307

\section{Questo documento è stato generato automaticamente il 9 septembre 2021.}

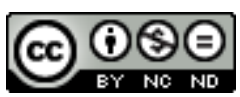

Studi Francesi è distribuita con Licenza Creative Commons Attribuzione - Non commerciale - Non opere derivate 4.0 Internazionale. 


\title{
Bruno Blanckeman, Sylvie Germain : le livre des livres
}

\author{
Elisa Bricco
}

\section{NOTIZIA}

BRUNO BLANCKEMAN, Sylvie Germain : le livre des livres, «Lendemains», Dossier : Les mutations esthétiques du roman contemporain français, 27, 2002, 107/108, pp. 86-96.

1 La complessità dei primi romanzi di Sylvie Germain, Le Livre des Nuits e Nuit-d'Ambre, è l'oggetto di questo studio: romanzo - i due libri ne formano in fondo uno solo - della modernità perché ricalca gli orientamenti della letteratura contemporanea e, al tempo stesso, se ne allontana per inserirsi in una linea che ha radici nell'origine del genere.

2 Infatti, nel primo testo due traiettorie si affiancano: la storia del libro e quella dei personaggi. L'intertestualità e la metanarrazione scorrono in filigrana nel racconto della saga dei Péniel, famiglia che attraversa la Storia tra la fine del XIX secolo e il XX, e ne subisce e asseconda i movimenti. Il romanzo genealogico si ramifica e la struttura si arricchisce di personaggi e avvenimenti, che si moltiplicano senza però sovraccaricare l'intreccio. Ma Le Livre des nuits non è solo questo, molteplici istanze narrative, stilistiche, generiche si accavallano e attraversano il testo, penetrando poi anche in Nuit-d'Ambre: la realtà e l'immaginario, l'affabulazione, la prosa e la poesia. La linea finzionale del primo romanzo viene invertita nel secondo dove si compie una saga al negativo, la distruzione totale della famiglia.

3 In questo intenso romanzo la scrittrice interroga l'uomo e la sua storia, affiancando e intaccando la narrazione romanzesca con il meraviglioso e l'inspiegabile: l'irruzione di elementi meravigliosi serve da contrappunto e da variazione della materia raccontata, illustra l'infinita varietà dei possibili della realtà e dell'immaginazione. Allo stesso modo anche la prosa è intaccata dall'irruzione della poesia, che contribuisce a sovvertire l'ordine del racconto, ad allargare il campo d'azione della scrittura e della significazione. 
4 Molteplici sono le linee di forza del racconto e le problematiche affrontate e messe in discussione, tra le quali una profonda interrogazione del Soggetto (che d'altronde percorre tutta la narrativa contemporanea), e una rivisitazione della questione etica del male attraverso la sua esplicita messa in scena. Il tutto viene continuamente detto e messo in discussione in un gioco di va e vieni in cui non è possibile trovare asserzioni definitive, ma solo tentativi di descrizione e di messa a punto. Così anche lo stesso statuto della narrazione è continuamente messo in discussione, stravolto e pervertito in un processo nihilistico che, attraverso il linguaggio, investe l'uomo e il mondo, l'essere e l'altro. 